\title{
IMAGENS DA AVALIAÇÃO DO ENSINO E APRENDIZAGEM A PARTIR DO ENCONTRO ENTRE SUJEITOS
}

\author{
Images of the evaluation of teaching and learning from the \\ Meeting between subjects
}

Francisco de Assis Alencar Mota ${ }^{1}$

\begin{abstract}
RESUMO: A avaliação da aprendizagem escolar constitui, no domínio das ciências da educação, um dos temas polêmicos, que suscita curiosidade em relação à sua prática, sendo também objeto de pesquisa. Abordar o fenômeno avaliativo, a partir dos rituais, significa discutir os problemas essenciais de natureza teórica, simbólica, didática e pedagógica. Disso, propôs-se um estudo, a partir de relatos de pesquisa, em consistência dos rituais de avaliação, onde a voz dos alunos soou mais intensamente para dizer o que pensam, sentem e sugerem àqueles que ousam propor avaliações. Sem dúvida, a transcrição fonética seguinte almeja ser apontamentos para novas discussões à guisa das observações e relatos de pesquisas. Espera-se, destarte, que a leitura crítica e continuada tenha encanto na participação efetiva de educandos e educadores.
\end{abstract}

Palavras-chave: avaliação, rituais, ensino e aprendizagem.

ABSTRACT: In the field of educational sciences, the evaluation of school learning is one of the controversial themes, which provokes curiosity about its practice and is also the subject of research. To approach the evaluative phenomenon, from the rituals, means to discuss the essential problems of theoretical, symbolic, didactic and pedagogical nature. From this, a study was proposed, based on research reports, on the consistency of evaluation rituals, where the students' voices sounded more intensely to say what they think, feel and suggest to those who dare to propose evaluations. Undoubtedly, the following phonetic transcription aims to be notes for further discussions in the light of observations and research reports. It is hoped, therefore, that critical and continued reading has charm in the effective participation of learners and educators.

Key-words: evaluation, rituals, teaching and learning.

\footnotetext{
${ }^{1}$ Bacharel em Serviço Social (UECE); licenciado em Língua Portuguesa (UECE); bacharel em Direito (UNIFOR); especialista em Direito Administrativo (UGF); especialista em Direito Penal e Processo Penal (FGF); especialista em Direito Constitucional (AVM Faculdade Integrada); mestre em Educação Brasileira (UFC).
} 


\section{INTRODUÇÃO}

O dia a dia das pessoas é acompanhado de imagens que se formam a partir da interação entre sujeito e objeto, ou da relação entre sujeitos, ou ainda, do produto entre o vivido e o concebido².

A relação entre o vivido e o concebido traduz melhor as imagens que foram produzidas, na última década, através de um estudo de caso, tendo como universo populacional os estudantes das duas únicas turmas do terceiro ano, do ensino médio, do turno noturno, do Colégio Instituto de Educação do Ceará - IEC, situado em Fortaleza, a, nas quais se encontram as concepções de avaliação, bem como os rituais que as acompanham.

O presente estudo é parte do relatório da Dissertação de Mestrado do autorrelator, apresentada ao Programa de Pós-Graduação em Educação Brasileira, da Universidade Federal do Ceará, com área de concentração em Avaliação Educacional e linha de pesquisa a avaliação do ensino e aprendizagem.

O objetivo geral foi desvendar o significado da avaliação, a partir do que pensam, sentem e sugerem os sujeitos investigados. Para alcançá-lo e por ser a avaliação educacional um dos temas polêmicos, passível de indagações, inferências e descobertas, transitou-se pelos caminhos metodológicos próprios da pesquisa qualitativa, sendo a sala de aula o ambiente naturalístico, fonte de inúmeras informações, acontecimentos e, até mesmo, encontros e desencontros entre os sujeitos da pesquisa.

Decorrentemente, preocupou-se o pesquisador em registrar, durante todo o processo de investigação e de forma contínua, o maior número possível de descrições referentes às manifestações dos sujeitos, numa interação dinâmica de fatos e acontecimentos em cujas expressões foram encontrados significados, permitindo, consequentemente, a organização dos dados em categorias de análise, entre elas, os rituais de avaliação, que é foco de atenção deste escrito.

À investigação ousou o pesquisador chamar de um "íntimo" encontro entre sujeitos, haja vista ter sido o momento em que se intensificou o esforço do

\footnotetext{
${ }^{2}$ Sintagmas atinentes ao espaço de representação que, na visão fenomenológica, são análises espaciais centradas no sujeito subjetivo, referenciando que o pensar e a ação do sujeito perpassam a possibilidade da existência de representações de cunho social.
} 
pesquisador em abrilhantar o conhecimento de avaliação à luz de um amplo referencial teórico, produzido por autores que se destacam na abordagem da temática, com ênfase ao estudo do Ritual ${ }^{3}$.

Usou-se o termo "intensificou" para acentuar que, antes mesmo da coleta de dados, já se servia o pesquisador dos conhecimentos em epígrafe. Daí o relato de que, concomitantemente à busca das informações, já se visitava a literatura existente com o intuito de que os resultados de pesquisa apresentados reunissem certas condições, como coerência, consistência teórica e objetivação (não objetividade), de forma a dar valor científico ao estudo sob tela.

As abordagens a seguir sobre o cotidiano da sala de aula, espaço privilegiado do investigador para inferir sobre o tema avaliação, terá aporte teórico o manancial de informação advindo da Antropologia Cultural, de onde se puderam extrair significações acerca da vasta lista de dados observacionais ritualizados, decorrentes das práticas avaliativas.

\section{OS RITUAIS}

A tendência para perceber o ritual simplesmente como uma rotina ou hábito é um equívoco, ou uso falacioso do termo ritual, isto é, uma maneira genuína de comportamento ritualizado, o que em sendo observado apenas em sua aparência não interessa ao discurso de que aqui se cuida, posto que:

Os rituais possuem um significado além da informação transmitida. São considerados como apontando para além de si mesmos, dotando rotinas e costumes de um significado mais amplo (MCLAREN, 1991, p.77).

Embora se perceba que as pessoas em geral sintam a necessidade de permanência, constância, a vida delas, quando em sociedade, é histórica. Daí o termo ritual ser um conceito difuso e frequentemente impalpável, passível de assédio por problemas de definição, os quais o têm perseguido por anos.

Todavia, nenhum de nós escapa da jurisdição do ritual, pois a cada instante estamos sob o seu impacto, por isso se engajar em um ritual, para homens e

\footnotetext{
${ }^{3}$ Perspectivado em Mclaren (1991), os rituais, enquanto formas de significação representada, capacitam os atores sociais a demarcar, negociar e articular sua existência fenomenológica como seres sociais, culturais e morais.
} 
mulheres, é uma necessidade humana. As origens do ritual em quaisquer sociedades nada mais são do que os significados destilados, encarnados em ritmos, gestos, símbolos e metáfora.

Mesmo sabendo que os rituais variam de cultura para cultura, eles são imperecíveis. Pode-se até dizer que são mais velhos que a própria história da humanidade, mas são o que resta, haja vista surgirem das coisas ordinárias da vida, presentes, inclusive, nas vidas industrial e comercial modernas.

O próprio ato de teorizar, observar, pesquisar, por exemplo, são gestos ritualísticos, ainda que acompanhados de ideologia (s). Daí os rituais serem parte da ordem natural das coisas, bem como consequências das ações humanas, como a rotina de trabalho, dos hábitos alimentares, regras de sala de aula etc. $E$ a maneira pela qual ritualizamos nossas vidas é cultura somatizada, ou seja, cultura enraizada em nossos atos e até mesmo em nossas expressões corporais.

Quem não se lembra daquele (a) professor (a) posicionado na parte mais alta da sala de aula, "respirando um ar mais puro que seus alunos", de braços cruzados e olhar sisudo, determinando, através de sua expressão física, que é um signo linguístico, o silêncio no ambiente?

É bem verdade que a maior parte das descrições acerca dos rituais se apresenta de maneira estática, o que pressupõe a necessidade de ser superada por ideias, significados, inferências que a ressituem numa epistemologia emergente do gesto, símbolo e metáfora. Noutras palavras, seria apontar para que os rituais pudessem ser visualizados sob a óptica do movimento. Daí asseverar que:

\footnotetext{
Um ritual não é simplesmente uma idéia misteriosa ou uma abstração piedosa preservada no breviário de algum padre de paróquia (...) Não está necessariamente ligada a experiências noéticas que são inefáveis ou a gestos misteriosos, invocações ou purificações que cercam o tomar de pão e vinho (...) Os rituais são parte da vida humana cotidiana, incluindo atividades seculares (MCLAREN, 1991, p. 70).
}

O lodaçal conceitual ou mesmo a discrasia definicional, na qual o termo ritual aparece interminavelmente enrascado, alerta para a necessidade de se desenvolver uma perspectiva de análise que não seja ampla com risco de perda de referencial para a explicação de certos objetos, mas que contenha suficiência para interpretar, 
no caso concreto, o cotidiano da sala de aula, especialmente em momentos de avaliação.

Da mesma forma, não se pode definir ritual apenas como um ato repetitivo, limitado, congelado, desprovido de significações e reflexões. Essa forma de visualizar o ritual há muito foi defendida e reproduzida por teóricos funcionalistas, que se referiam aos rituais como meros reflexos de aspectos ou componentes "normais" da estrutura social. Em giro outro, os rituais:

São inerentemente sociais e políticos, não podendo ser entendidos isolados do modo como os indivíduos se situam biográfica e historicamente em várias tradições de mediação, por exemplo, clã, gênero, ambiente do lar, cultura do grupo de companheiros (McLAREN, 1991, p. 73).

Contemporaneamente, apontam-se os rituais para o "além de", ou seja, podem encarnar e transmitir certas ideologias ou visões de mundo, mas também inverter normas e valores da ordem social dominante; possuem um significado além da informação transmitida, pois embora sejam, por vezes, descritos como acompanhando a rotina ou os procedimentos instrumentais, os símbolos rituais são considerados como apontamentos para além de si mesmos, dotando rotinas e costumes de significações ampliadas.

Nessa esteira serão apresentadas algumas pegadas ritualísticas, a partir da compreensão dos símbolos, que iluminarão as abordagens vindouras, juntamente com o esforço do pesquisador, almejando que as imagens da avaliação do ensino e aprendizagem, a partir do encontro entre sujeitos, sejam discorridas de maneira fundamentada, fulcrada nos estudos dos Rituais, mas também no conhecimento produzido sobre a avaliação educacional.

\section{ENTRANDO NA SALA DE AULA}

Mesmo que este item sugira o passaporte direto às salas de aula, é devido o esclarecimento de que prévios contatos foram necessários para que se procedesse à pesquisa em comento, tendo como ambiente de coleta de informações, de estudo e de observação o "locus" privilegiado onde acontece o ensino e aprendizagem.

O contato inicial com o ambiente de pesquisa ocorreu através da Coordenadora Pedagógica, juntamente com a Diretora Geral da escola alhures 
mencionada. Citadas profissionais atenderam ao pesquisador com atenção e presteza, ouvindo-Ihe acerca dos propósitos contidos no projeto de pesquisa, embora tais explicações esbarrassem em limitações de ordem estrutural apontadas pelas educadoras.

A escola, como já era do conhecimento do investigador, tinha como filosofia de trabalho o intercâmbio entre as pesquisas e cursos oriundos das Universidades, em consistência do que propunha o seu Projeto Político Pedagógico, que facilitou o imediato ingresso do sujeito investigador no interior da Instituição, tanto na sala de aula propriamente dita, como em outros espaços físicos, como sala de professores, biblioteca, ambiente cultural etc.

Outrossim, o objeto em estudo era assunto latente, posto que a Secretaria de Educação do Estado do Ceará, em atendimento à Lei de Diretrizes e Bases da Educação Nacional, alvitrou novos enfoques aos procedimentos avaliativos, o que "mexeu" diretamente na forma tradicional de avaliação pelos professores. Isso pôde ser constatado quando dos diálogos travados entre o pesquisador e alguns dos docentes, nos momentos de intervalos de aula, especificamente, na sala dos professores.

Os comentários arrolados pelos mestres, no tocante à avaliação, ora se reportavam à impossibilidade de registrar processualmente as habilidades e competências demonstradas pelos educandos, alegando a contingência de alunos, ora pela falta de preparação dos professores para conduzirem seus trabalhos de avaliação pela óptica formativa e, especialmente, por não abrirem mão dos rituais de avaliação que atravessa toda uma história de vida. A esse respeito Perrenoud (1999, p. 17) faz o seguinte pronunciamento:

\footnotetext{
Raros são os professores que se opõem resoluta e abertamente a uma pedagogia diferenciada ou a uma avaliação formativa. Todavia, só há adesão com a condição de que essas sejam efetivadas "acima do mercado", sem comprometer nenhuma das funções tradicionais de avaliação, sem tocar na estrutura escolar (...) sem exigir novas qualificações dos professores.
}

Segundo McLaren (1991, p. 85), "muitos rituais têm sido chamados de seculares e exibem as qualidades formais de repetição.". As manifestações observadas pelo pesquisador no espaço da sala de aula não pareciam fugir dessa assertiva, pois quase todas as aulas eram conduzidas de forma ritualizada: primeiro 
a chamada (diário escolar), depois o registro na lousa, tempo dado pelo professor para que os alunos reproduzissem seus escritos para os cadernos, explicações dos conteúdos pelos professores, por fim, exercícios, os quais, na maioria das vezes, atrelavam-se a procedimentos avaliativos.

No decorrer das aulas, outras manifestações se apresentavam como hábitos e rotinas, a saber: pelo professor - "prestem atenção! Isto vai cair na prova! Não vou responder, vocês têm que pesquisar! Estudem que o exame do ENEM vem aí! Essa matéria cai no vestibular!"; pelo aluno tem-se - "professor, qual a matéria que vai cair na prova? Para que vai servir isso na minha vida, professora? Esse exercício vai valer algum ponto? A senhora vai passar uma prova bem 'facilzinha', né professora?".

Dos rituais acima, infere-se que os sujeitos da educação cumprem a função de moldura, enquadrando-se na concepção bancária de educação (FREIRE, 2013), ou seja, em lugar de comunicar-se, o professor enuncia comunicados e depósitos; os educandos, meros figurantes, recebem (muitas vezes pacientemente), memorizam e repetem, sendo estas as margens de ação que lhes sobram ao processo de ensino e aprendizagem.

É de se observar, ainda, que a concepção de aprendizagem, timidamente exposta, recai na simples assimilação servil do conhecimento, ou do armazenamento do saber tal qual foi repassado em sala de aula, permitindo deduzir que a aprendizagem dos alunos resume-se na retenção do conhecimento estabelecido, que deve ser devolvido pelo aluno ao educador no momento da avaliação, ratificando, assim, a concepção supramencionada.

McLaren (1991), em seu estudo etnográfico sobre alunos de uma escola católica, no Canadá, definiu como eixo tipológico de ritos de instrução quatro Estados Interativos, aos quais chamou de Estado de "Esquina de Rua", Estado de Estudante, Estado de Santidade e Estado de Casa. Não cabe aqui o aprofundamento dos fundamentos que os embasam, todavia importa ressaltar que 0 termo "Estado" foi empregado para sugerir estilos de interação com o ambiente escolar. O "Estados" consistem em conjuntos organizados de comportamentos, dos quais emerge um sistema central de práticas vividas.

No processo de investigação em tela, não foi difícil perceber, do produto entre o vivido e o concebido, características que se assemelhavam ao que foi vivenciado pelo teórico em referência. Nas aulas de Ciências, como Química e Cadernos Cajuína, V. 4, N. 2, 2019, p.110 - 124. 
Física, por exemplo, observou-se claramente a inquietação e indisciplina dos estudantes por não entenderem nada (ou quase nada) do que o professor falava ou escrevia.

A sensação do investigador é de que, naquele momento, os alunos estavam sendo violentados, já que era cristalina a torcida para que a aula terminasse. Inferese daí que aos alunos faltava conhecimento prévio para entender o atual; ao mesmo tempo em que se percebe que o conteúdo dessas disciplinas não pertencia ao universo cultural dos mesmos, isto é, não havia interação entre o que se ensina e sua aplicação prática, tampouco relação de continuidade.

Em decorrência, os estudantes conversavam demasiadamente durante as aulas, liam revistas, levantavam-se da carteira, deslocavam-se ao banheiro e ao bebedouro, enfim "atrapalhavam" a qualquer custo as aulas ministradas pelos professores das pré-faladas disciplinas, demonstrando com esse comportamento o Estado de "Esquina de Rua" que nada mais é do que "um conjunto de atributos que quando colocados juntos constituem uma determinada maneira de se relacionar com ambientes, eventos e pessoas" (MCLAREN, 1991, p. 132).

Por outro lado, demonstrações de interesse, comprometimento e motivação pelos alunos foram registradas, quando as aulas eram ministradas por meio dos mais variados recursos didáticos. llustrando essa reflexão, a professora de Biologia, numa determinada aula, além de ter trazido ao debate um assunto de interesse coletivo (neste caso, sobre reprodução humana), trouxe consigo diferentes apontamentos de estudo, como livros alternativos, revistas e gravuras o que raramente pôde ser visto em outras aulas.

O comportamento demonstrado pelos alunos era, em parte, aquele que McLaren (1991) denominou de Estado de Estudante. A expressão "em parte" porque a amplitude de sua significação remete também para as categorias da obediência, prêmio, punição, o que não se acopla ao exemplo último. Todavia, a disciplina, a concentração e o interesse dos alunos pela aprendizagem foram as características assinaladas pelo sujeito relator e que se amoldam a esse conjunto ritualizado denominado de Estado de Estudante.

Convém, ainda, registrar outros rituais de avaliação. Pelo calendário escolar, a cada dois meses havia uma semana reservada só para avaliações. Os professores, de modo geral, ao entrar em sala de aula, pediam aos educandos que 
organizassem as carteiras de forma a ficarem todas enfileiradas. O motivo era óbvio: o desmantelamento de "esquemas de cola".

As provas só eram entregues após pairar totalmente o silêncio na sala de aula. Diga-se de passagem, este era o único momento em que os alunos se mantinham "quietos". Após a entrega das provas, viam-se comportamentos distintos por parte dos alunos: uns roendo unhas, com demonstrações de tensão e apreensão, outros olhando para os lados, como se estivessem tentando lembrar-se de alguma resposta, mas também havia aqueles com aparência de inteira concentração.

Os procedimentos avaliativos efetuados a partir dos rituais acima, aos quais se atribui o título de processo avaliativo desvirtuado, acarretam para o aluno situações emocionais as mais variadas possíveis, consoante comentários a seguir:

O estado emocional, a tensão e a punição nos quais o aluno se envolve, mediante situações de um processo avaliativo desvirtuado, parece não ser preocupação da escola e do professor, talvez por desconhecerem as conseqüências que podem acarretar para a vida futura do estudante (FERREIRA, 2009, p. 56-57).

A ansiedade também sabota todos os tipos de desempenho acadêmico (...) a apreensão pré-prova interfere com a clareza do pensamento e a memória necessária para estudar eficazmente e durante a prova perturba a clareza mental essencial para sair-se bem (GOLEMAN, 1995, p. 96-97).

A descrição do comportamento dos alunos é inevitavelmente resultante do fator emocional causado pelo medo de provas, medo das notas, medo do fracasso, medo da reprovação. Nesse sentido, Luckesi (2011, p. 94) colaciona que:

Sob a forma de verificação tem se utilizado o processo de aferição da aprendizagem de forma negativa, à medida que tem servido para desenvolver o ciclo do medo nas crianças e jovens, pela constante ameaça de reprovação.

Em sede de observação, constatou-se que os rituais de avaliação eram os que mais se operavam nas relações instrucionais. Antes mesmo de começar a prova, precisamente nos corredores do Colégio, já se viam alunos confabulando uns com os outros acerca de como iriam pôr em prática os "esquemas de cola". 
Os professores, por suas vezes, comportavam-se nos momentos de avaliação de forma bastante heterogênea, ou seja, uns ficavam transitando pela sala, entre as carteiras, com braços cruzados e olhar de seriedade excessiva, não dando nenhuma margem aos que almejavam "colar", pondo a avaliação "a serviço da punição, discriminação e com data marcada para o veredicto" (ABRAHÃO, 2001, p. 47).

Outros, embora demonstrassem certa preocupação com os rituais de organização de sala de aula e prezassem pela não conversa durante os momentos de provas e testes, não ficavam de maneira explícita fiscalizando se os alunos faziam qualquer tipo de consulta a livros ou a quaisquer outros materiais didáticos; ao contrário, entregavam a (s) folha (s) de prova e depois sentavam aos seus birôs esperando apenas pela devolução das mencionadas provas pelos alunos.

$\mathrm{Na}$ verdade, quaisquer das posturas acima remetem, de forma matricial, ainda que inconscientemente, ao postulado teórico do professor e à concepção que ele tem dessas práticas pedagógicas, haja vista ser no espaço da sala de aula que o educador concretiza sua experiência, seus valores, seu comprometimento ético e social e onde vivência diferentes interações. Portanto: "O que o professor faz em avaliação é condicionado pela concepção que tem desse processo mais amplo de ensino e aprendizagem" (LUDKE, 2013, p. 30).

É também determinada pela sua história, pela sua cultura e conjuntura social onde se desenvolveu, ou seja, toda verdade do professor é um reflexo daquilo que ele vivenciou historicamente. Segundo Cunha (2017, p. 44), "aquilo que a pessoa diz ou faz está moldado consciente ou inconscientemente pela situação social.".

Pertine mencionar que no início da pesquisa, pela ocasião da observação, o pesquisador percebeu que os alunos the olhavam como um intruso, isto é, alguém que estava ali não para observar esse momento singular e contributivo, mas para ajudar o professor a fiscalizar a sala de aula. No trilhar do ano letivo, já não existia mais essa suspeita pelos alunos, pois a função do investigador já se fazia mais clara para eles.

Os rituais de avaliação foram observados nos mais variados momentos, abrangendo os períodos denominados de semana de provas, bem como as situações comuns do cotidiano escolar. Eis algumas transcrições de falas de professores e alunos:

É melhor prestarem atenção, porque vou pedir isso na prova! 
Ficam conversando e na hora da prova não fazem nada! Depois vem todo choroso pedindo uns pontinhos para mim! A hora de perguntar é agora, na prova não lembro mais de nada! (falas dos professores).

Professora, esse exercício vale algum ponto? A avaliação pode ser feita em equipe? Essa matéria vai ser cobrada na prova?". (falas dos alunos).

É importante assinalar que tanto professores como alunos exaltavam o termo prova e não avaliação. É bem verdade que esse signo linguístico não é pronunciado por um simples acaso. Por trás dos fonemas e suas representações gráficas escondem-se as direções ideológica e política, mas também a própria história de vida de cada um deles.

Nesse caso, convém refletir acerca das teorias em avaliação que explicam os sentidos desses termos. Segundo Hoffmann (2014, p. 49), "a ênfase excessiva na palavra e no ponto de vista do professor e a concentração de esforços na testagem de resultados finais" constituem entraves ao processo de avaliação do ensino e aprendizagem.

No caso concreto, professores e alunos, ao falarem de provas, deixavam subjacente a ideia de uma avaliação do tipo classificatória que nada mais é do que a correção de tarefas e provas do aluno para conferir respostas certas e erradas e, com base nisso, tomar decisões quanto ao seu aproveitamento escolar, ou seja, sua aprovação ou reprovação, ou ainda, manter no aluno o status de competente ou fracassado. Isso:

Resulta num educador que não se vê como partícipe do movimento, da trajetória percorrida pelo aluno, mas como sinalizador dos pontos de chegada. Posiciona-se nas linhas de chegada com o seu olhar medidor, desconfiado, pronto a registrar milímetros de diferença entre cada um dos que entram na competição (HOFFMANN, 2014, p. 28-29).

Da mesma forma, a avaliação da aprendizagem, efetuada através do uso indiscriminado do instrumento prova e a expressão dos resultados através de notas, passa a ser considerada, muitas vezes, pelo aluno, como ameaça e punição. Segundo Luckesi (2011), há professores que elaboram provas com o intuito de apenas testar o aluno, ou ainda, atribuir-Ihe pontos de bonificação em virtude de certas atividades escolares, tendo, por trás dessa prática avaliativa, o próprio sistema de ensino e suas ideologias. 
Pela exemplificação supra, a avaliação assume característica de um hiato, isto é, realiza-se em momentos estanques e distanciados, fruto da relação professoraluno, descaracterizando, por seu turno, sua preciosa validade pedagógica: promover o crescimento do aluno como cidadão, levando em conta sua singularidade e contextualização.

Numa das aulas observadas, uma professora pediu para que os alunos lessem algumas páginas de um determinado livro e, em seguida, fizessem um resumo destacando as ideias principais, estabelecendo como termo de entrega o final da aula.

Os alunos, por suas vezes, além de não entenderem o que liam, não sabiam como destacar as solicitadas ideias. A professora, após fazer a chamada mantinhase sentada a sua mesa, fazendo algumas anotações que não pareciam guardar relação com a atividade que passara em sala de aula. Segundo Ferreira (2002, p. 17), é dessa forma que a função clássica do professor se evidencia, melhor dizendo, é através da aula expositiva tradicional, bem como do processo de avaliação por meio de provas, exames, padronização de tarefas e limite de tempo que o professor rege suas aulas.

Há de mencionar, ainda, a existência de rituais de exames e provas, apontados para a competição, rivalidade, aos quais os alunos são submetidos em consignação com o sistema rígido e opressivo, onde os métodos de ensino são apenas prelações e repetições verbais e memorísticas.

A bem da verdade, as práticas pedagógicas acima descritas já se arrastam por séculos e, em alguns casos, sem muitas intenções de mudanças, embora seja reconhecida, em realidades específicas (na maioria das vezes, em escolas particulares) a existência de grandes esforços com vista à superação dessa prática.

Todavia, nas últimas décadas, o significado e a validade dos métodos tradicionais de avaliação têm sido contestados e até perdido centímetros de credibilidade e simpatia. Assim, alguns educadores têm primado por redirecionar os seus métodos de ensino, inclusive suas práticas avaliativas, superando a função seletiva, eliminatória e classificatória, em favor do sentido dinâmico e reflexivo do processo de avaliação do ensino e aprendizagem.

Insofismavelmente, no curso da investigação pouco se observou a respeito da ampliação do conceito de avaliação. Apontamentos para um novo ritual foram visualizados de maneira bem discreta, principalmente, por parte dos professores, Cadernos Cajuína, V. 4, N. 2, 2019, p.110 - 124. 
como no caso da disciplina de Sociologia, onde o professor, pontualmente, adentrou na sala, distribuiu um texto contendo duas laudas, leu-o, juntamente com os alunos, dirimiu dúvidas, suscitou reflexões e debates, deixando-os rigorosamente cientes da tarefa proposta contida no final do texto.

Rituais como chamada de presença, marcação de provas, pontos de bonificação, alinhamentos de carteiras entre outros, não se faziam presentes no método utilizado pelo professor da disciplina de Sociologia. Ao contrário, os próprios alunos culturalmente ritualizados é que se encarregavam de indagar o mestre acerca dos pré-falados ritos de sala de aula.

Por mais que não se tenha encontrado, no trabalho de investigação, dados que enriqueçam a postura em avaliação apontada para formação, construção e mediação do conhecimento, é importante conclamar para que se pense a avaliação sempre como um momento provisório do conhecimento.

Tê-la como um processo, implica o conhecimento de toda a história de aprendizagem do educando, fazendo da avaliação um momento de reflexão do aluno e, no caso do professor, o conhecimento de toda a sua empreitada rumo ao ensino, revertendo esse campo específico do conhecimento - a avaliação - em favor dos sujeitos, fornecendo-lhes possibilidades para as ações de refletir e avaliar, que nada mais são do que planejar e estabelecer objetivos educacionais.

\section{CONSIDERAÇÕES FINAIS}

A divulgação de parte da pesquisa aqui consignada partiu da assertiva de que há ainda o que dizer sobre o objeto em questão, não para ser mais um discurso, mas para ampliar o conceito e o alcance do tema em perspectivas de análise, a partir das expressões dos sujeitos. O alcance é todos aqueles que direta ou indiretamente se vejam envolvidos com a avaliação educacional, particularmente, no contorno do ensino e aprendizagem escolar.

Os rituais de avaliação, como chamada, marcação de provas, pontos de bonificação em decorrência de atividades em sala de aula, alinhamento de carteiras em dias de prova, fiscalização de provas pelos professores, a cultura linguística dos sujeitos quando se reportam às avaliações mereceram destaque para essa apresentação. No pensamento de McLaren (1991) os rituais se nutrem da 
experiência dos homens e crescem conjunturalmente, a partir das mediações culturais e políticas, moldando os contornos de grupos e instituições.

A ação de avaliar não constitui tarefa fácil. É condição sine qua non para refletir sobre o valor que uma avaliação pode produzir, dada a concepção de conhecimento que está subjacente à ação de avaliar. Ainda que ela aponte para uma prática cumpridora de uma função desvirtuada, acredita-se na sua superação, ou seja, numa avaliação capaz de fazer com que todos adquiram o saber e o apropriem reflexivamente. A avaliação deverá construir oportunidades reais de demonstração do que os sujeitos sabem e como eles elaboraram seus saberes.

É nessa dinâmica que a avaliação se transforma em atividade de aprendizagem conectada à reflexão, da qual todos saem beneficiados, porque ela é fonte de conhecimento e impulso para descortinar cada vez mais os saberes, devendo ser sempre um exercício intencional, pois está relacionada a pessoas em situações de aprendizagem.

O rumo que deve tomar esta temática não se pode, com certeza, asseverar, até porque o momento não é de finalização, mas de construção. Entretanto, indícios confirmam que muitos sistemas educacionais caminham para uma avaliação mais integrada com uma pedagogia renovada. Hodiernamente, sente-se que a avaliação tradicional perde guarida, cedendo espaço para uma prática avaliativa centrada no educando, como partícipe do processo de ensino e aprendizagem.

Abre-se, então, a esperança para a construção de outro ritual: a proposta de uma avaliação formativa, a qual, segundo Perrenoud (1999), "está no âmago das tentativas de pedagogia diferenciada e de individualização dos percursos de formação". Nessa direção é, no mínimo, incontestável a afirmação de que a lógica formativa tem ganhado importância nos debates educacionais brasileiros. Urge avançar!

\section{REFERÊNCIAS}

ABRAHÃO, M. H. M. B. (Org). Avaliação e erro construtivo libertador: uma teoriaprática includente em educação. Porto Alegre: EDIPUCRS, 2001, 75p.

CUNHA, M. I. de. 0 bom professor e sua prática. 24. ed. Campinas-SP: Papirus, 2017. 160p. 
FERREIRA, L. Retratos da avaliação: conflitos, desvirtuamentos e caminhos para a superação. 2. ed. Porto Alegre, Mediação, 2009, 128p.

FREIRE, P. Pedagogia do oprimido. 54. ed. Rio de Janeiro: Paz \& Terra, 2013. $256 p$.

GOLEMAN, D. Inteligência emocional. Tradução de Marcos Santarrita. 7. ed. Rio de Janeiro: Objetiva, 1995.

HOFFMAN, J. M. L. Avaliação mediadora: uma prática em construção da pré-escola à universidade. 33. ed. Porto Alegre: Mediação, 2014. 200p.

LUCKESI, C. C. Avaliação da aprendizagem escolar: estudos e proposições. 22. ed. São Paulo: Cortez, 2011. 272p.

LUDKE, M.; ANDRÉ, M. D. A. Pesquisa em educação: abordagens qualitativas. 2. ed. São Paulo: EPU, 2013. 128p.

McLAREN, P. Rituais na escola: em direção a uma economia política de símbolos e gestos na educação. Petrópolis-RJ: Vozes, 1991. 397p.

PERRENOUD, P. Avaliação: da excelência à regulação das aprendizagens - entre duas lógicas. Porto Alegre: Artes Médicas, 1999. 